\title{
Longitudinal Study of Umbilical and Portal Venous Blood flow to the Fetal Liver: Low Pregnancy Weight Gain is Associated With Preferential Supply to the Fetal Left Liver Lobe
}

\author{
JÖRG KESSLER, SVEIN RASMUSSEN, KEITH GODFREY, MARK HANSON, AND TORVID KISERUD
}

\begin{abstract}
Department of Clinical Medicine [J.K., S.R., T.K.], University of Bergen, N-5020 Bergen, Norway; Department of Obstetrics and Gynecology [J.K., S.R., T.K.], Haukeland University Hospital, N-5021 Bergen, Norway; Medical Birth Registry of Norway [S.R.], University of Bergen and the Norwegian Institute of Public Health, N-5018 Bergen, Norway; Division of Developmental Origins of Health and Disease [K.G., M.H.], University of Southampton, Southampton, SO 16 6YD, United Kingdom
\end{abstract}

\begin{abstract}
Recent data suggest that umbilical venous perfusion of the fetal liver has an important influence on fetal growth and postnatal liver function, and that maternal factors in late pregnancy modify this circulation. In a longitudinal study of 160 low-risk pregnancies, we determined how umbilical and portal venous blood flows to the fetal liver changed during gestation, and examined the hypothesis that maternal body mass index and pregnancy weight gain influenced fetal liver blood flows. We measured blood flows in the umbilical and portal veins, left portal branch, and ductus venosus using ultrasound. Normalizing for estimated fetal weight, fetal liver total venous blood flow fell from 84 to $57 \mathrm{~mL} \cdot \mathrm{min}^{-1} \cdot \mathrm{kg}^{-1}$ during 21-39 wk of gestation; toward term the portal contribution increased (from 14 to 20\%) and the umbilical contribution fell, whereas distribution between the left and right liver lobes was stable, 60\%/ $40 \%$. Greater flow of nutrient-rich umbilical venous blood to the liver was associated with higher birth weight and neonatal ponderal index. Maternal body mass index was not related to fetal liver blood flows, but low pregnancy weight gain strongly influenced flow distribution between the right and left liver lobes, sparing the left lobe and increasing the difference between lobes by 16\%. (Pediatr Res 63: 315-320, 2008)
\end{abstract}

$\mathrm{T}_{\mathrm{c}}$ he developmental origins of health and disease hypothesis established a link between an adverse intrauterine environment and cardiovascular disease in adult life $(1,2)$. There is strong evidence from epidemiologic studies and animal experiments that an adverse intrauterine environment is associated with raised levels of cardiovascular risk factors controlled by the liver (3). The role of the fetal liver for intrauterine growth and development has therefore come into focus of research.

In fetal sheep, experimental reduction in umbilical venous liver perfusion results in decreased synthesis of insulin-like growth factors by the fetal liver, decreasing the cellular proliferation rate in peripheral tissues and impairing fetal growth $(4,5)$. In human fetuses, venous liver blood flow was shown to be modulated by maternal diet and body composition (6).

Received April 5, 2007; accepted October 20, 2007.

Correspondence: Jörg Kessler, M.D., Ph.D., Department of Clinical Medicine, Division for Obstetrics and Gynecology, Haukeland University Hospital. N-5021 Bergen, Norway; e-mail: jorg.kessler@kk.uib.no.

This study received financial support from the National Health Council, Norway and Haukeland University Hospital, Bergen.
The fetal liver receives venous blood from the umbilical and portal veins (PVs). The umbilical vein (UV) directs nutrient-rich placental blood predominantly to the left liver lobe, whereas nutrient-depleted blood from the PV is directed to the right liver lobe (7). This selective perfusion pattern is thought to be the main reason for differences in micro architecture (8), hematopoiesis (9) and gene and enzyme expression $(10,11)$.

Although single components of the venous liver circulation such as umbilical blood flow (12-14) and shunting through the ductus venosus (DV) $(15,16)$ have been investigated earlier, little is known about the distributions of umbilical and portal blood flows in the human fetus.

The aim of the present study was to study simultaneously the umbilical and portal venous circulations and the blood flow distribution to the liver lobes in the second half of human pregnancy. Based on the previous demonstration of modulation of liver blood flow by maternal diet and body composition we tested - among other factors - the hypothesis that pregnancy weight gain influenced the venous blood supply of the liver.

\section{MATERIALS AND METHODS}

The present study is part of a larger project addressing venous blood supply to the liver in human fetuses. The study protocol was approved by the Regional Committee for Medical Research Ethics (REK-Vest 04/3837) and the women were recruited after informed written consent. We previously reported on DV flow velocities (17) and blood flow in the PV (18) and the left PV (LPV) (19). ${ }^{1}$

Subjects. Women attending the ultrasound department for the routine scan between 17 and $20 \mathrm{wk}$ of gestation were invited to the present study, of which a total of 160 healthy pregnant women consecutively entered the study during the period of August 2004-July 2005. Gestational age was assessed by ultrasound in the second trimester (20). Reasons for exclusion were twins, fetuses with a malformation or chromosomal aberration, maternal chronic diseases (i.e., hypertension, diabetes, rheumatic or autoimmune diseases, dyslipidemia), or previous obstetric complications (i.e., preeclampsia, growth restriction, placental abruption, gestational diabetes, delivery $<37$ wk of gestation). Participants had four to five ultrasound examinations at 4 weeks intervals starting at $20-22 \mathrm{wk}$ of gestation. Each session lasted $60 \mathrm{~min}$. After birth, information on gender, birth weight (BW), length, Apgar score, mode of delivery, transfer to the neonatal intensive care unit (NICU), and neonatal complications were collected from the medical records. Participants were asked their own birth weight (available for 130 of 160 subjects).

Abbreviations: BW, birth weight; DV, ductus venosus; LPV, left portal vein; $\mathbf{P V}$, portal vein (main stem); UV, umbilical vein 
Measurement. A Sonos 7500 ultrasound machine (Phillips, Seattle, Washington) with a $3.5-\mathrm{MHz}(2-6 \mathrm{MHz})$ curved linear transducer including color Doppler $(2.5 \mathrm{MHz})$ and pulsed Doppler $(3 \mathrm{MHz})$ facilities was used for the study. The high-pass filter was set at $50 \mathrm{~Hz}$. The mechanical index (MI) and the thermal index for soft tissue (TIS) were mostly at the level of 1.1 or below. In a few obese participants, occasionally higher energy output was needed increasing TIS and MI to 1.4.

Vessel diameter and flow velocities were measured at: 1) the intraabdominal portion of the UV; 2) the inlet of the DV; 3) the LPV; 4) the PV (Fig. 1). Vessel diameter was measured in a perpendicular insonation to the vessel wall. Diameter was measured repeatedly (UV, LPV, PV: median 4 times, DV: median 5) to reduce random error (21) and the mean diameter was used for further analysis. At the same site, with an insonation along the vessel axis, flow velocities (time-averaged maximum flow velocity, TAMXV) were measured using pulsed Doppler. The angle of insonation was kept as low as possible and always $\leq 30$ degrees. The measurement techniques for the UV, the DV, the LPV, and PV have been described in detail $(15,18,22)$.

The volume blood flow $(Q)$ was calculated for the sites described above $\left(Q_{\mathrm{UV}}, Q_{\mathrm{DV}}, Q_{\mathrm{LPV}}\right.$, and $Q_{\mathrm{PV}}$, respectively) as: $Q=\pi(D / 2)^{2} h \mathrm{TAMXV}(h$, velocity profile; $h=0.5$ for UV $(23,24), \mathrm{LPV}$, and PV $(18) ; h=0.7$ for DV $(25,26))$. The total venous blood supply of the liver $\left(Q_{\text {liver }}\right)$ was calculated as: $Q_{\text {liver }}=\left(Q_{\mathrm{UV}}-Q_{\mathrm{DV}}\right)+Q_{\mathrm{PV}}$. The venous blood flow to the left liver lobe $\left(Q_{\text {left liver }}\right)$ was calculated as: $Q_{\text {left liver }}=Q_{\mathrm{UV}}-\left(Q_{\mathrm{DV}}+Q_{\mathrm{LPV}}\right)$ and to the right liver lobe $\left(Q_{\text {right liver }}\right): Q_{\text {right liver }}=Q_{\mathrm{PV}}+Q_{\mathrm{LPV}}$. The fraction of umbilical blood shunted through the DV $\left(F_{\mathrm{DV}}\right)$ was calculated as: $F_{\mathrm{DV}}=Q_{\mathrm{DV}} / Q_{\mathrm{UV}} \times$ $100 \%$. The umbilical and portal fraction of the total venous blood supply of the liver $\left(F_{\mathrm{UV}}, F_{\mathrm{PV}}\right)$ was calculated as: $F_{\mathrm{UV}}=\left(Q_{\mathrm{UV}}-Q_{\mathrm{DV}}\right) / Q_{\text {liver }} \times 100 \%$ and $F_{\mathrm{PV}}=Q_{\mathrm{PV}} / Q_{\text {liver }} \times 100 \%$. Blood flow to the right and left liver lobes in relation to the total venous blood supply of the liver $\left(F_{\text {left liver }}, F_{\text {right liver }}\right)$ was: $F_{\text {left liver }}=Q_{\text {left liver }} / Q_{\text {liver }} \times 100 \%$ and $F_{\text {right liver }}=Q_{\text {right liver }} / Q_{\text {liver }} \times 100 \%$. The blood flow was normalized for fetal weight. For this purpose, the percentile related to the BW and gender was found (27) and used to estimate fetal weight (28) at the time of the earlier ultrasound examination.

Maternal prepregnancy body mass index (BMI) was calculated as weight $(\mathrm{kg}) /$ height $(\mathrm{m})^{2}$. Average maternal pregnancy weight gain was calculated by subtracting the weight registered latest in pregnancy from prepregnancy weight divided by the gestational age when the latest weight was measured. Neonatal ponderal index was calculated as BW $(\mathrm{kg}) / \mathrm{length}(\mathrm{m})^{3}(29)$.

Statistics. The statistical power of the study was based on assumptions as published earlier for the present study population (17). Statistical analysis was performed using SPSS (Statistical Package for the Social Sciences, SPSS Inc, Chicago, IL). Multilevel modeling was used to construct mean and percentile curves for each variable by gestational age using the MlWin program (MIWin, Centre for Multilevel Modeling, University of Bristol, UK) following prin-

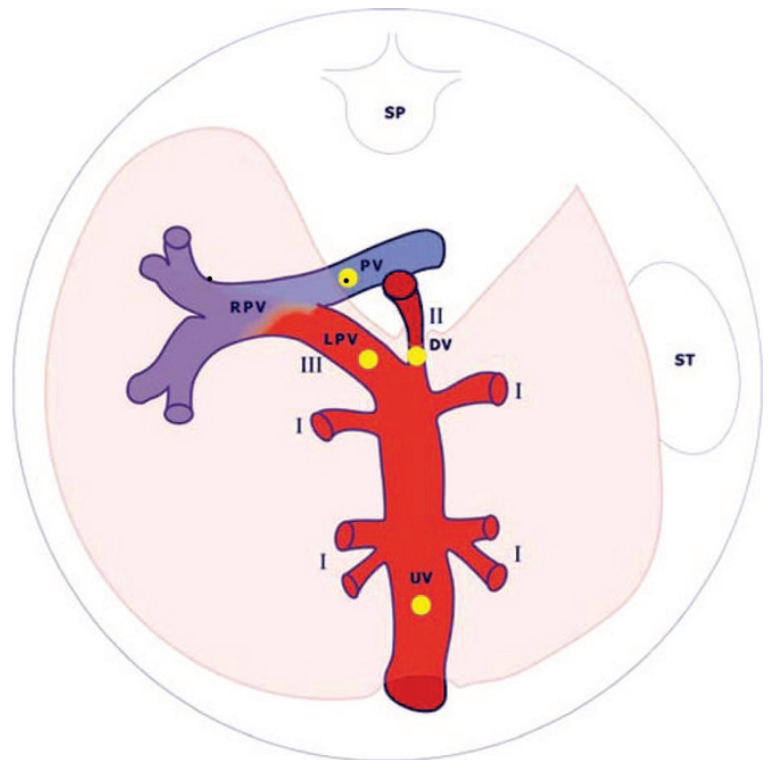

Figure 1. Venous blood supply of the fetal liver with level of oxygenation, sequence of perfusion (I-III), and measure sites (yellow circles). High oxygen saturation (red color), low oxygen saturation (blue color), and mixture of blood with high and low saturation (purple color). UV, umbilical vein; DV, ductus venosus; LPV, left portal vein; RPV, right portal vein; PV, main stem of the portal vein; ST, stomach; SP, spine. ciples described previously (17). To assess the possible effect of maternal and fetal variables (fetal gender and tertiles of maternal BW, prepregnancy BMI, pregnancy weight gain, BW, and neonatal ponderal index) on the flow variables, we included these possible determinants as indicator variables in the multilevel regressions models, which describe the mean curves. Indicator variables with significant improvement in the goodness of fit to the models, as assessed by the deviance statistics $\left(\chi^{2}\right.$ with $\left.p<0.05\right)$, were considered to significantly influence the flow.

\section{RESULTS}

Median gestational age at delivery was $40+3 \mathrm{wk}$ (range $33+3$ to $42+4)$; mean $( \pm$ SD) BW was $3550 \pm 480 \mathrm{~g}$ and ponderal index was $27.71 \pm 2.72 \mathrm{~kg} / \mathrm{m}^{3}$. The participating women had a mean BW of $3360 \pm 520 \mathrm{~g}$, a prepregnancy BMI of $23.4 \pm 3.8$ and mean average pregnancy weight gain of $0.36 \pm 0.14 \mathrm{~kg} / \mathrm{wk}$. Further characteristics of the study population have been published earlier (18). A total 655 examinations were done (median 4 per participant, range 1-5). The success rate for the flow measurements and calculated flow parameters was between 84 and $97 \%$.

The total venous blood supply of the fetal liver increased from 35 to $189 \mathrm{~mL} / \mathrm{min}$ during the second half of pregnancy (Fig. 2A). The UV and LPV blood flows showed a similar pattern of increase, rising from 44 to $201 \mathrm{~mL} / \mathrm{min}$ (UV) and 10 to $44 \mathrm{~mL} / \mathrm{min}$ (LPV) (Fig. 2B,C). Total venous liver blood flow, UV, and LPV flows did not increase after $36 \mathrm{wk}$ (Fig. $2 A-C$ ). The blood flow in the DV rose continuously from 13 $\mathrm{mL} / \mathrm{min}$ at $21 \mathrm{wk}$ to $45 \mathrm{~mL} / \mathrm{min}$ at $39 \mathrm{wk}$ (Fig. $2 D$ ). The total blood flow to the left liver lobe increased from $19 \mathrm{~mL} / \mathrm{min}$ at $21 \mathrm{wk}$ to $104 \mathrm{~mL} / \mathrm{min}$ at $36 \mathrm{wk}$ with no further significant change (Fig. 3A). In contrast, blood flow to the right liver lobe increased throughout the whole observation period from 14 $\mathrm{mL} / \mathrm{min}$ at $21 \mathrm{wk}$ to $85 \mathrm{~mL} / \mathrm{min}$ at $39 \mathrm{wk}$ (Fig. $3 A$ ).
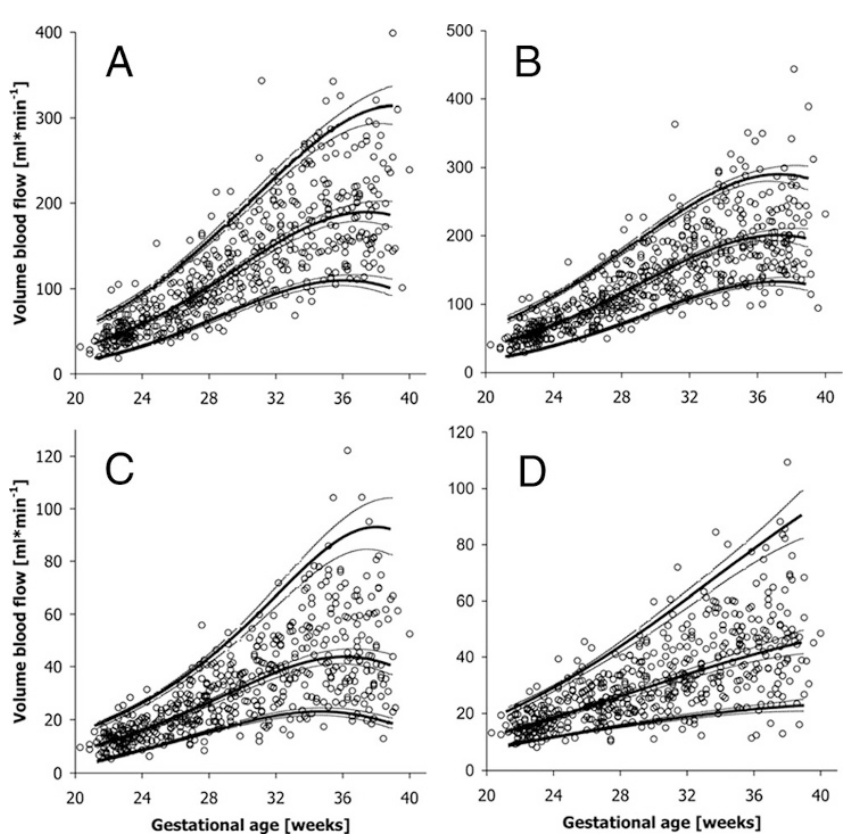

Figure 2. Volume blood flow ( $\mathrm{mL} / \mathrm{min}$ ) presented with 5 th, 50th, and 95 th percentile (solid lines) and 95\% confidence interval (dashed lines). A, Total venous liver; $B$, umbilical vein; $C$, left portal branch; $D$, ductus venosus. Data based on $525(A), 574(B), 542(C), 543(D)$ observations in 160 low-risk pregnancies. Not shown in Figure $2 C$ : one observation at $39+4$ wk with reversed flow in the left portal branch of $23 \mathrm{~mL} / \mathrm{min}$. 
Normalized for estimated fetal weight, the total venous blood supply to the fetal liver decreased from $84 \mathrm{~mL} \cdot \mathrm{min}^{-1} \cdot \mathrm{kg}^{-1}$ at $21 \mathrm{wk}$ to $57 \mathrm{~mL} \cdot \mathrm{min}^{-1} \cdot \mathrm{kg}^{-1}$ at $39 \mathrm{wk}$ (Fig. $4 A$ ). Normalized UV, LPV, and DV blood flows also decreased during the second half of pregnancy from 104 to $60 \mathrm{~mL} \cdot \mathrm{min}^{-1} \cdot \mathrm{kg}^{-1}$ (UV), 24 to $14 \mathrm{~mL} \cdot \mathrm{min}^{-1} \cdot \mathrm{kg}^{-1}(\mathrm{LPV})$, and 33 to $15 \mathrm{~mL} \cdot \mathrm{min}^{-1} \cdot \mathrm{kg}^{-1}$ (DV) (Fig. 4B-D). As a consequence, the blood flow to the left liver lobe normalized for estimated fetal weight decreased from 47 to $30 \mathrm{~mL} \cdot \mathrm{min}^{-1} \cdot \mathrm{kg}^{-1}$ during the second half of pregnancy (Fig. $3 B$ ) and normalized blood flow to the right liver lobe decreased from 35 to $27 \mathrm{~mL} \cdot \mathrm{min}^{-1} \cdot \mathrm{kg}^{-1}$ (Fig. $3 B$ ).

The mean fraction of umbilical venous blood shunted through the DV was $31 \%$ at $21 \mathrm{wk}$ of gestation, falling to a nadir of $21 \%$ at $33 \mathrm{wk}$ before increasing slightly to $24 \%$ at $39 \mathrm{wk}$ (Fig. 5). The contribution of the UV to the venous blood supply of the liver
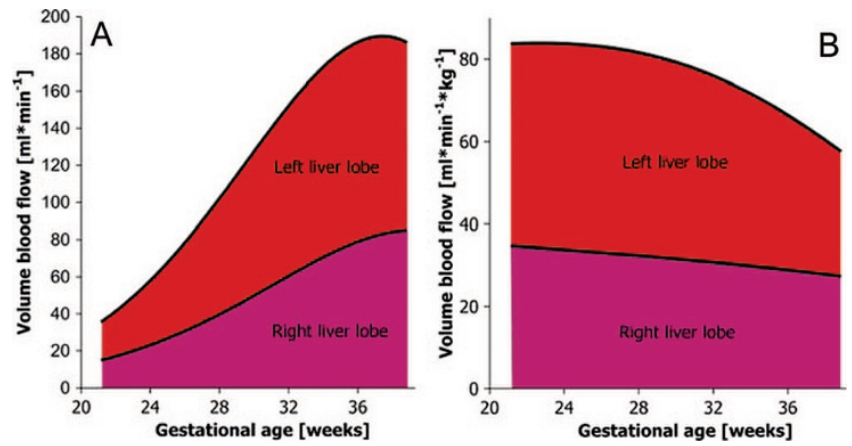

Figure 3. $A$, Venous volume blood flow (mL/min); $B$ : blood flow normalized for fetal weight $\left(\mathrm{mL} \cdot \mathrm{min}^{-1} \cdot \mathrm{kg}^{-1}\right)$ to the left and right liver lobe based on 508 (left lobe) and 529 (right lobe) observations in 160 low-risk pregnancies. Data presented with 50th percentile (solid lines).
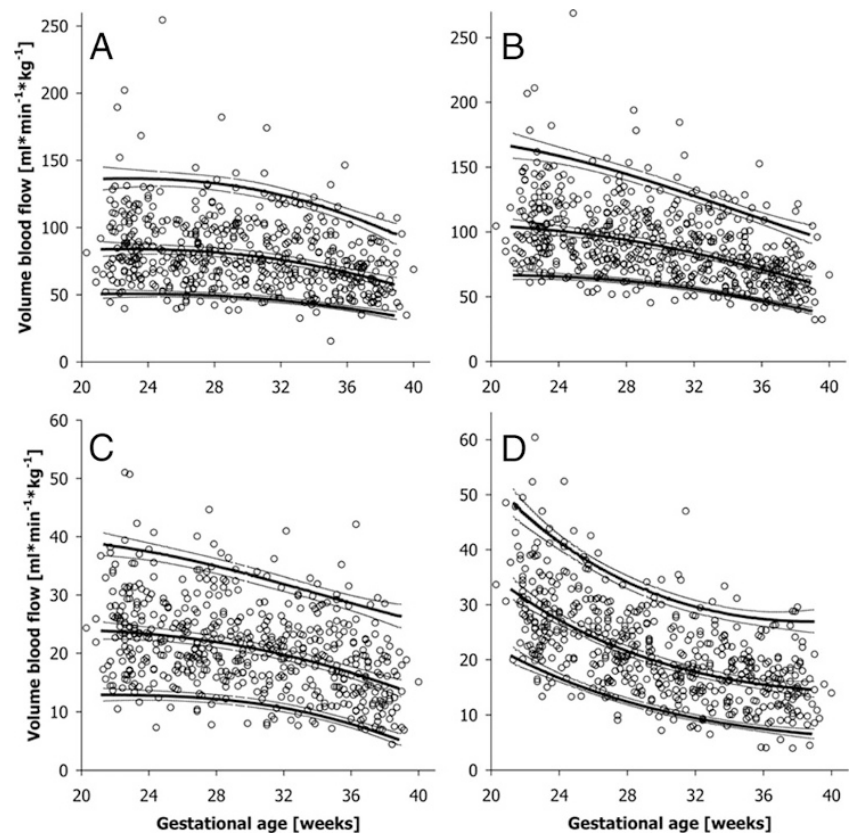

Figure 4. Blood flow normalized for fetal weight $\left(\mathrm{mL} \cdot \min ^{-1} \cdot \mathrm{kg}^{-1}\right)$ presented with 5th, 50th, and 95th percentile (solid lines) and 95\% confidence interval (dashed lines). $A$, Total venous liver; $B$, umbilical vein; $C$, left portal branch; $D$, ductus venosus. Data based on $525(A), 574(B), 542(C), 543(D)$ observations in 160 low-risk pregnancies. Not shown in Figure $2 C$ : one observation at $39+4$ wk with reversed flow in the left portal branch of 7.9 $\mathrm{mL} \cdot \mathrm{min}^{-1} \cdot \mathrm{kg}^{-1}$. was $86 \%$ at midgestation decreasing after $32 \mathrm{wk}$ to $80 \%$ at $39 \mathrm{wk}$ (Fig. 6). Correspondingly, the PV accounted for $14 \%$ of the venous blood supply at $21 \mathrm{wk}$ followed by a continuous increase after $32 \mathrm{wk}$ to $20 \%$ near term (Fig. 6). The proportion of venous blood directed to the two liver lobes was fairly stable throughout the observation period. The left liver lobe received about $60 \%$ and the right $40 \%$ (Fig. 7).

The possible influence of fetal and maternal variables on the venous liver blood flow was addressed. Infant sex was not related to any of the flow parameters throughout gestation, but BW was positively related to total venous liver flow, UV,

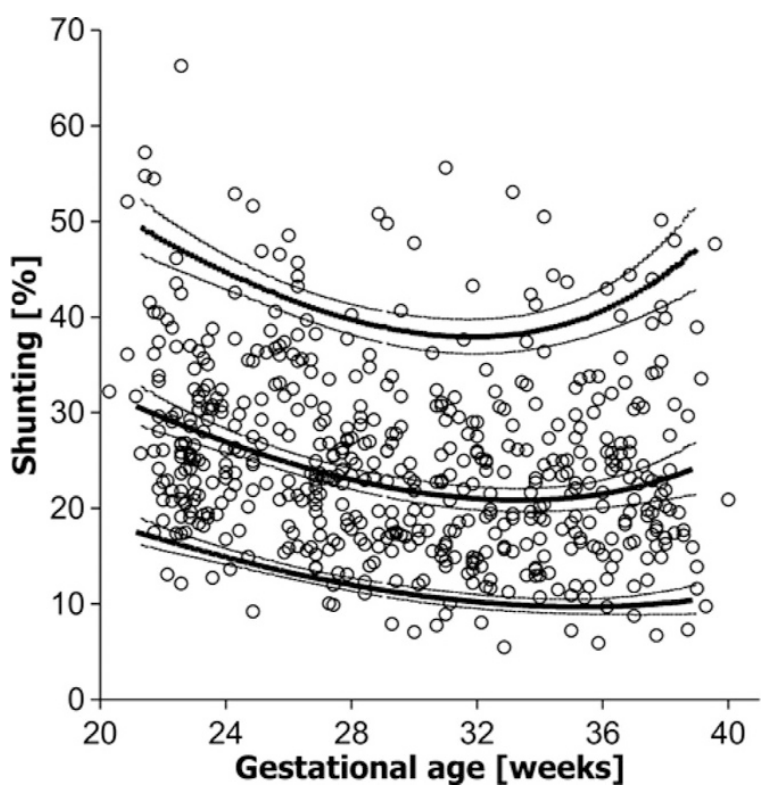

Figure 5. Fraction of umbilical blood shunted through the ductus venosus, based on 534 observations in 160 low-risk pregnancies. Data presented with 5th, 50th, and 95th percentile (solid lines) and 95\% confidence interval (dashed lines).

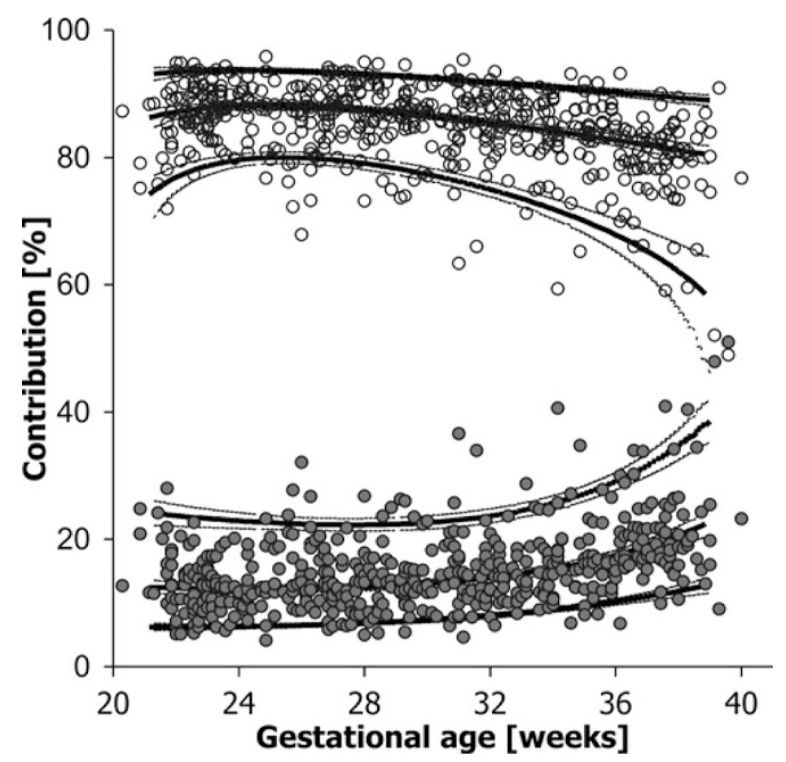

Figure 6. Contribution of the main portal stem (filled circles) and the umbilical vein (open circles) to the total venous blood supply of the fetal liver, based on 522 observations in 160 low-risk pregnancies. Data presented with 5th, 50th, and 95th percentile (solid lines) and 95\% confidence interval (dashed lines). 


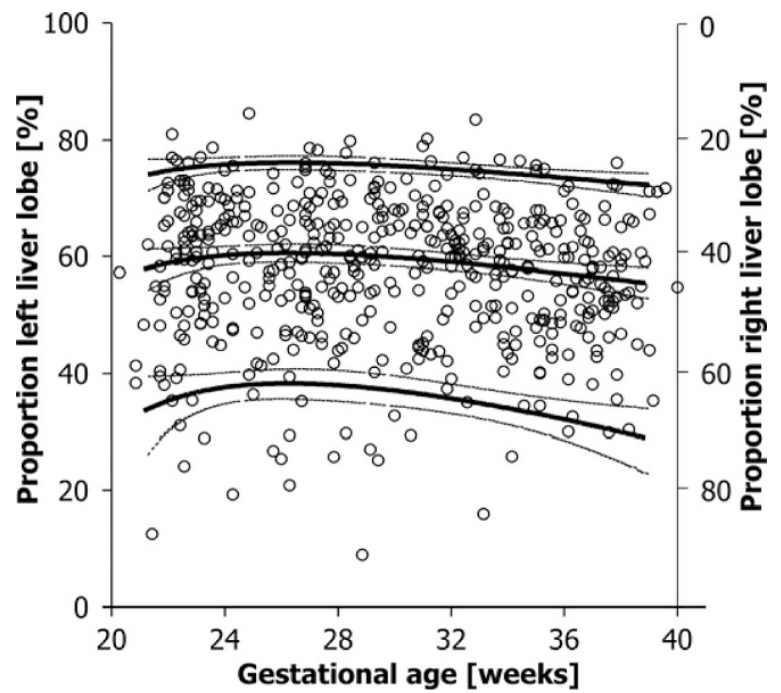

Figure 7. Proportion of total venous blood supply directed to the left and right liver lobes, based on 497 observations in 160 low-risk pregnancies. Data presented with 5th, 50th, and 95th percentile (solid lines) and 95\% confidence interval (dashed lines).

Table 1. Effect of birth weight on venous blood flow to the fetal liver and ductus venosus based on deviance statistics for the entire observation period (21-39 wk of gestation)

\begin{tabular}{|c|c|c|c|c|}
\hline \multirow{3}{*}{$\begin{array}{l}\text { Volume blood } \\
\text { flow }(\mathrm{mL} / \mathrm{min})\end{array}$} & \multicolumn{3}{|c|}{ Birth weight (g) } & \multirow[b]{3}{*}{$p$} \\
\hline & $<3380$ & $3380-3770$ & $>3770$ & \\
\hline & \multicolumn{3}{|c|}{ Tertile mean at 32-wk gestation } & \\
\hline Total venous liver & 141.2 & 153.5 & 162.8 & $<\mathbf{0 . 0 0 1}$ \\
\hline Umbilical vein & 152.1 & 169.8 & 180.1 & $<\mathbf{0 . 0 0 0 1}$ \\
\hline Ductus venosus & 32.3 & 34.1 & 35.0 & 0.15 \\
\hline Left portal vein & 34.1 & 38.2 & 41.5 & $<\mathbf{0 . 0 0 0 6}$ \\
\hline Main portal stem & 19.4 & 21.3 & 22.3 & $<\mathbf{0 . 0 0 0 1}$ \\
\hline Right liver lobe & 58.5 & 61.0 & 62.8 & $<0.0001$ \\
\hline Left liver lobe & 85.8 & 95.0 & 102.7 & $<\mathbf{0 . 0 5}$ \\
\hline
\end{tabular}

The values for $32 \mathrm{wk}$ are given to illustrate the magnitude of the effects. Values in bold indicate $<0.05$.

LPV, PV flows, right and left liver lobe flows (Table 1). Neonatal ponderal index was related to LPV flow (Table 2). Furthermore, newborns with low ponderal index had decreased UV and left liver lobe flows (Table 2).

Maternal BW and prepregnancy BMI had no influence on any of the flow parameters throughout gestation. However, analyzing a subgroup of observations from $35+0$ wk onwards, lower maternal prepregnancy BMI was associated with lower DV shunt fraction $(p<0.05)$.

Lower pregnancy weight gain had strong graded relations with lower DV, LPV, PV, and right liver lobe flows. Participants with low pregnancy weight gain did, however, have the highest left liver lobe flow; as a consequence, the difference between flows to the right and left lobes was $31.9 \mathrm{~mL} / \mathrm{min}$ in women with low pregnancy weight gain, as compared with $26.8 \mathrm{~mL} / \mathrm{min}$ in those with average or above average weight gain (Table 3, Fig. 8A), a difference of $16 \%$. When we analyzed the blood flows normalized for estimated fetal weight, this difference was even larger, with a $37 \%$ greater difference between right and left lobe flows in those with low pregnancy weight gain $\left(18.1 \mathrm{~mL} \cdot \mathrm{min}^{-1} \cdot \mathrm{kg}^{-1}\right)$, as compared with those with average or above average weight
Table 2. Effect of ponderal index at birth on venous blood flow to the fetal liver and ductus venosus based on deviance statistics for the entire observation period (21-39 wk of gestation)

\begin{tabular}{|c|c|c|c|c|}
\hline \multirow{3}{*}{$\begin{array}{l}\text { Volume blood flow } \\
\qquad(\mathrm{mL} / \mathrm{min})\end{array}$} & \multicolumn{3}{|c|}{ Ponderal index $\left(\mathrm{kg} / \mathrm{m}^{3}\right)$} & \multirow[b]{3}{*}{$p$} \\
\hline & $<26.86$ & $26.86-28.57$ & $>28.57$ & \\
\hline & \multicolumn{3}{|c|}{ Tertile mean at 32 -wk gestation } & \\
\hline Total venous liver & 183.3 & 195.1 & 192.8 & 0.17 \\
\hline Umbilical vein & 159.5 & 171.4 & 171.4 & $<\mathbf{0 . 0 2}$ \\
\hline Ductus venosus & 33.0 & 33.2 & 35.7 & 0.058 \\
\hline Left portal vein & 37.1 & 37.5 & 38.7 & $<0.0001$ \\
\hline Main portal stem & 19.9 & 21.0 & 21.5 & 0.11 \\
\hline Right liver lobe & 76.5 & 77.0 & 79.2 & 0.55 \\
\hline Left liver lobe & 83.9 & 92.9 & 90.6 & $<0.04$ \\
\hline
\end{tabular}

The values for $32 \mathrm{wk}$ are given to illustrate the magnitude of the effects. Values in bold indicate $<0.05$.

Table 3. Effect of pregnancy weight gain on venous blood flow to the fetal liver and ductus venosus based on deviance statistics for the entire observation period (21-39 wk of gestation)

\begin{tabular}{lcccc}
\hline & \multicolumn{3}{c}{ Pregnancy weight gain $(\mathrm{kg} / \mathrm{wk})$} & \\
\cline { 2 - 3 } & $<0.330$ & $0.330-0.425$ & $>0.425$ & \\
\cline { 2 - 3 } & \multicolumn{3}{c}{ Tertile mean at 32-wk gestation } & $p$ \\
\hline $\begin{array}{c}\text { Volume blood flow } \\
\text { (mL/min) }\end{array}$ & & & & \\
Total venous liver & 153.0 & 152.1 & 154.0 & 0.25 \\
Umbilical vein & 165.0 & 167.1 & 171.1 & 0.05 \\
Ductus venosus & 33.2 & 33.7 & 34.1 & $<\mathbf{0 . 0 0 0 1}$ \\
Left portal vein & 36.0 & 38.3 & 40.0 & $<\mathbf{0 . 0 0 0 1}$ \\
Main portal stem & 20.6 & 20.9 & 21.2 & $<\mathbf{0 . 0 0 0 1}$ \\
Right liver lobe & 58.5 & 61.0 & 62.8 & $<\mathbf{0 . 0 0 0 2}$ \\
Left liver lobe & 90.4 & 87.2 & 90.2 & $<\mathbf{0 . 0 0 0 1}$ \\
Fraction of total venous & & & & \\
$\quad$ liver flow (\%) & & & & \\
Right liver lobe & 38.9 & 41.4 & 41.3 & $<\mathbf{0 . 0 0 0 1}$ \\
Left liver lobe & 60.9 & 58.5 & 58.7 & $<\mathbf{0 . 0 0 0 1}$ \\
\hline
\end{tabular}

The values for $32 \mathrm{wk}$ are given to illustrate the magnitude of the effects. Values in bold indicate $<0.05$.

gain $\left(13.2 \mathrm{~mL} \cdot \mathrm{min}^{-1} \cdot \mathrm{kg}^{-1}\right.$ ) (Table 3, Fig. 8B). Pregnancy weight gain was positively related to normalized LPV flow and inversely related to normalized total venous liver flow, UV, DV, and PV flows (Table 3).

\section{DISCUSSION}

In the present study, we have a complete view of the venous supply to the fetal liver and have shown that the UV was the principal source throughout gestation but with an increased contribution from the PV after 32 wk of gestation. During gestation, we found a stable blood flow distribution between the left and right liver lobes, receiving $60 \%$ and $40 \%$ of the venous blood, respectively. Lower maternal pregnancy weight gain was associated with sparing of the left liver lobe at the expense of the right.

Oxygenated nutrient rich blood returns from the placenta to the fetus via the UV. An increasing umbilical venous blood flow throughout gestation was found previously (1316,30,31). We found a similar development (Fig. 2B) and our results confirmed some of the previous studies $(14,15,31)$ and differed slightly from others $(13,16,30)$. The majority of the 

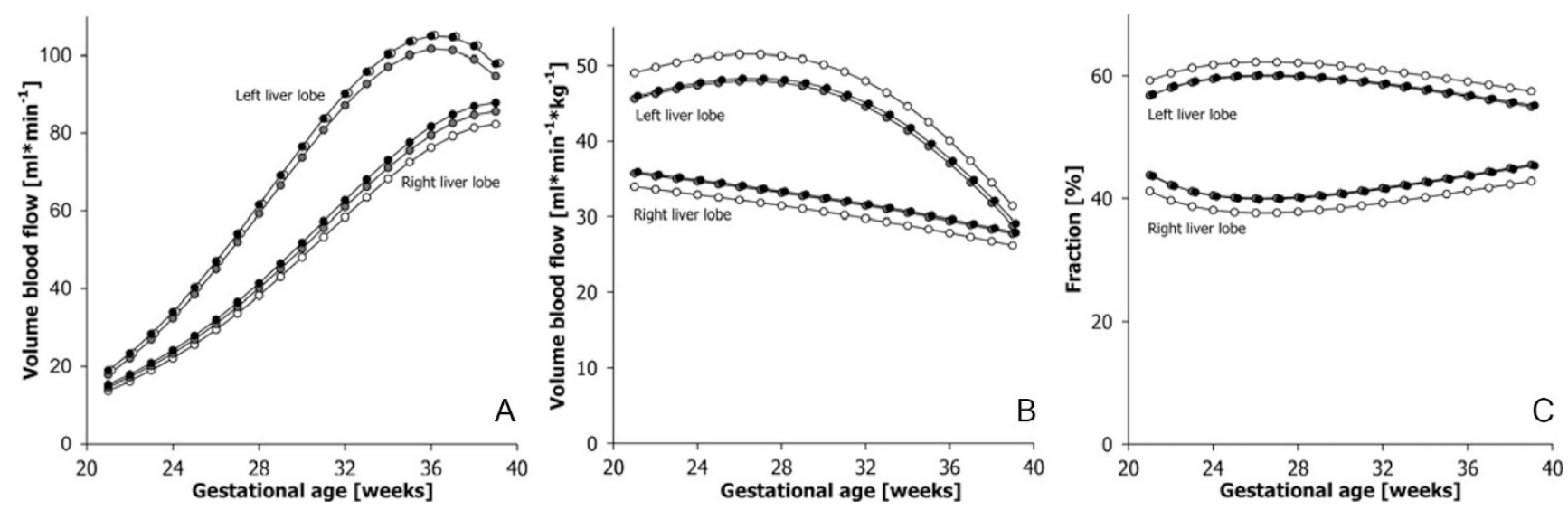

Figure 8. Influence of average pregnancy weight gain on volume blood flow to the left and right liver lobes in absolute terms $(A)$, normalized for fetal weight $(B)$, and on the proportion of total venous blood supply, directed to the left and right liver lobes $(C)$. Assessed by deviance statistics for the entire observation period (21-39 wk), $p<0.0001$. Tertiles for pregnancy weight gain; $\bigcirc, 0.330 \mathrm{~kg} / \mathrm{wk} ; \bigcirc, 0.330-0.425 \mathrm{~kg} / \mathrm{wk} ; \bigcirc,>0.425 \mathrm{~kg} / \mathrm{wk}$.

umbilical blood perfuses the liver $(70-80 \%)$ whereas a minor fraction is shunted through the DV (20-30\%) $(15,16)$. In agreement with these studies, we also demonstrated a decrease of the shunt fraction from $31 \%$ at midgestation to $24 \%$ at term indicating the high priority given to the liver perfusion $(69-76 \%)$.

Sequentially, umbilical blood is first directed to the left liver lobe (Fig. 1 [I], Fig. 3), then a fraction is shunted through the DV (Fig. 1 [II], Fig. 2D,4D) and the remainder flows through the left portal branch (Fig. 1 [III], Fig. 2C,4C) to the right liver lobe. The changes in the LPV seen in the present study (Table 1-3) support the vessel as a marker of the watershed between the left and right liver lobes (32). Although the left liver lobe is exclusively perfused by umbilical venous blood, both the splanchnic circulation (via the PV) and the umbilical circulation (via the left portal branch) contribute to the perfusion of the right liver lobe (Fig. 3).

As a consequence of the increasing blood flow both in the UV and the PV (18) during the observation period the total venous blood supply to the fetal liver increased during gestation (Fig. 2A); this increase was blunted after $36 \mathrm{wk}$, perhaps explaining the lack of a correlation between gestational age $(34+1$ to $38+6$ wk) and total venous liver flow in a previous study (22). To a large extent, the gestational increase in venous flow in the liver is explained by increasing fetal size. In fact, fetal weight gain accelerates more than flow, resulting in a relative flow decrease throughout gestation for UV, LPV, $\mathrm{DV}$, and total venous liver flows (Fig. $4 A-D$ ). The pattern of a relative reduction in flow with growing gestational age has been reported in previous studies of the umbilical circulation $(14-16,33)$ and appears to be linked to a reduced proportion of fetal cardiac output directed to the placenta (34). This is, however, partially compensated by an increasing $\mathrm{Hb}$ concentration (35) and a more efficient transplacental transport (36). In contrast to the umbilical circulation, we recently demonstrated that normalized blood flow in the PV showed an increase after 30-32 gestational weeks (18) signifying a more prominent role of the splanchnic circulation (Fig. 6). We interpret the shift toward a higher portal contribution as a gradual approximation to postnatal circulation. Despite the change in contribution from the $\mathrm{UV}$ and $\mathrm{PV}$, the proportion of blood directed to the left (60\%) and right liver lobes $(40 \%)$ was fairly stable during the second half of pregnancy. This is in agreement with a cross-sectional study done at $36 \mathrm{wk}$ of gestation (22), but at variance with another study, which used a different measurement technique (16), and with fetal sheep experiments (left versus right: 50/50\%) (7).

The venous liver perfusion may represent a mediator between intrauterine environment and fetal growth and metabolism. In fetal sheep the venous blood perfusion of the liver is linked to hepatic synthesis of insulin-like growth factors and peripheral cell proliferation (4). The positive correlation between UV, LPV, $\mathrm{PV}$, and total venous liver flow and BW fits with these experimental data and is in agreement with a previous study (6).

In human fetuses liver perfusion is apparently influenced by maternal body composition and diet (6). We found no overall effect of maternal prepregnancy BMI on venous liver perfusion, but analysis of the subgroup of measurements from $35+$ 0 wk toward term demonstrated a relationship with the DV shunt fraction, confirming a previous study (6). Furthermore, we found that maternal weight gain influenced a variety of flow parameters. Interestingly, fetuses of women with low weight gain during pregnancy had a higher blood flow to the left liver lobe (Table 3, Fig. 8A,B) and lower flow to the right liver lobe. Thus, low weight gain in pregnancy appeared to modify the venous distribution between the liver lobes giving priority to the left liver lobe (Table 3, Fig. $8 C$ ). The difference between flows to the right and left lobes was $16 \%$ greater in women with low pregnancy weight gain, as compared those with average or above average weight gain; the difference between right and left lobe flows normalized for estimated fetal weight was even larger (37\%). There was no association between neonatal ponderal index and blood flow to the right lobe, but infants with a low neonatal ponderal index had had a lower left lobe flow (Table 2). This suggests that the two lobes may play differing roles in the regulation of fetal growth.

It was recently shown, that pathways related to cell biogenesis, phospholipid biosynthesis and metabolism, protein biosynthesis and metabolism all are up-regulated in the left compared with the right liver lobe in fetal baboon (11). Thus, the distributional 
changes in response to low weight gain may be part of an adaptation to a relatively poorer intrauterine environment with impact on fetal liver function. Recently, subtle functional differences between the left and right liver lobes were detected in adult life and attributed to the different sources of venous blood supply to the liver lobes in fetal life (37). A shifted balance of venous perfusion within the fetal liver may therefore also have long-term consequences for liver function and link intrauterine environment with health and disease in adulthood.

The estimation of volume blood flow by ultrasound has potential sources of error mainly related to the diameter measurement. Repeat measurement has shown to reduce random error (21) and was practiced for all diameter measurements in the study. Because less susceptible to error than intensity weighted mean velocity, we used the time averaged $V_{\max }$ corrected by a velocity profile factor for flow calculation. The assumption that the velocity profile is parabolic, i.e., $h=0.5$, may not be valid under all conditions (38). However, three recent publications showed excellent agreement between both methods for flow calculation in the UV $(14,22)$ and the PV $(18)$, which is reassuring for the method applied in this study. The data presented in this study confirm the flow estimates of some recent studies $(14,15,22,31)$, but somehow lower than others $(13,16,30,33)$ possibly because of sampling site, insonation technique, and diameter measurements as discussed previously (14). Our results are partly different to those of Bellotti et al. (16) also in regard to the flow distribution between the left and right liver lobes. Although Haugen et al. (22) and the present study measured blood flow in the LPV, Bellotti et al. (16) sampled flow velocities immediately upstream to the DV. As mentioned by others major branches to the left liver lobe arise at this point and may interfere in the recording and accordingly skew the calculation of right and left liver lobe flows (22).

In conclusion, the UV is the principal source of venous blood for the fetal liver, but the PV plays an increasing role toward term, signifying an increasing priority of the splanchnic circulation. The flow distribution between the liver lobes was fairly stable during pregnancy, $60 \%$ to the left lobe, and $40 \%$ to the right. Pregnancy weight gain influenced flow distribution within the fetal liver, sparing the left lobe at the expense of the right lobe, with potential consequences for later liver function.

\section{REFERENCES}

1. Barker DJ, Osmond C 1986 Infant mortality, childhood nutrition, and ischaemic heart disease in England and Wales. Lancet 1:1077-1081

2. Godfrey KM, Barker DJ 2001 Fetal programming and adult health. Public Health Nutr 4:611-624

3. McMillen IC, Robinson JS 2005 Developmental origins of the metabolic syndrome: prediction, plasticity, and programming. Physiol Rev 85:571-633

4. Tchirikov M, Kertschanska S, Sturenberg HJ, Schroder HJ 2002 Liver blood perfusion as a possible instrument for fetal growth regulation. Placenta 23:S153-S158

5. Tchirikov M, Kertschanska S, Schroder HJ 2001 Obstruction of ductus venosus stimulates cell proliferation in organs of fetal sheep. Placenta 22:24-31

6. Haugen G, Hanson M, Kiserud T, Crozier S, Inskip H, Godfrey KM 2005 Fetal liver-sparing cardiovascular adaptations linked to mother's slimness and diet. Circ Res 96:12-14

7. Edelstone DI, Rudolph AM, Heymann MA 1978 Liver and ductus venosus blood flows in fetal lambs in utero. Circ Res 42:426-433

8. Emery JL 1963 Functional asymmetry of the liver. Ann NY Acad Sci 111:37-44
9. Emery JL 1956 The distribution of haemopoietic foci in the infantile human liver. J Anat 90:293-297

10. Ring JA, Ghabrial H, Ching MS, Shulkes A, Smallwood RA, Morgan DJ 1998 Propranolol elimination by right and left fetal liver: studies in the intact isolated perfused fetal sheep liver. J Pharmacol Exp Ther 284:535-541

11. Cox LA, Schlabritz-Loutsevitch N, Hubbard GB, Nijland MJ, McDonald TJ, Nathanielsz PW 2006 Gene expression profile differences in left and right liver lobes from mid-gestation fetal baboons: a cautionary tale. J Physiol 572:59-66

12. Gill RW, Kossoff G, Warren PS, Garrett WJ 1984 Umbilical venous flow in normal and complicated pregnancy. Ultrasound Med Biol 10:349-363

13. Barbera A, Galan HL, Ferrazzi E, Rigano S, Jozwik M, Battaglia FC, Pardi G 1999 Relationship of umbilical vein blood flow to growth parameters in the human fetus. Am J Obstet Gynecol 181:174-179

14. Acharya G, Wilsgaard T, Rosvold Berntsen GK, Maltau JM, Kiserud T 2005 Reference ranges for umbilical vein blood flow in the second half of pregnancy based on longitudinal data. Prenat Diagn 25:99-111

15. Kiserud T, Rasmussen S, Skulstad S 2000 Blood flow and the degree of shunting through the ductus venosus in the human fetus. Am J Obstet Gynecol 182:147-153

16. Bellotti M, Pennati G, De Gasperi C, Battaglia FC, Ferrazzi E 2000 Role of ductus venosus in distribution of umbilical blood flow in human fetuses during second half of pregnancy. Am J Physiol Heart Circ Physiol 279:H1256-H1263

17. Kessler J, Rasmussen S, Hanson M, Kiserud T 2006 Longitudinal reference ranges for ductus venosus flow velocities and waveform indices. Ultrasound Obstet Gynecol 28:890-898

18. Kessler J, Rasmussen S, Kiserud T 2007 The fetal portal vein: normal blood flow development during the second half of human pregnancy. Ultrasound Obstet Gynecol 30:52-60

19. Kessler J, Rasmussen S, Kiserud T 2007 The left portal vein as an indicator of watershed in the fetal circulation: development during the second half of pregnancy and a suggested method of evaluation. Ultrasound Obstet Gynecol 30:757-764

20. Johnsen SL, Rasmussen S, Sollien R, Kiserud T 2004 Fetal age assessment based on ultrasound head biometry and the effect of maternal and fetal factors. Acta Obstet Gynecol Scand 83:716-723

21. Kiserud T, Rasmussen S 1998 How repeat measurements affect the mean diameter of the umbilical vein and the ductus venosus. Ultrasound Obstet Gynecol 11:419-425

22. Haugen G, Kiserud T, Godfrey K, Crozier S, Hanson M 2004 Portal and umbilical venous blood supply to the liver in the human fetus near term. Ultrasound Obstet Gynecol 24:599-605

23. Kiserud T, Eik-Nes SH, Blaas HG, Hellevik LR, Simensen B 1994 Ductus venosus blood velocity and the umbilical circulation in the seriously growth-retarded fetus. Ultrasound Obstet Gynecol 4:109-114

24. Kiserud T 2005 Venous hemodynamics. In: Maulik D (ed) Doppler Ultrasound in Obstetrics and Gynecology. Springer-Verlag, Berlin, Heidelberg, New York, pp 57-67

25. Pennati G, Bellotti M, Ferrazzi E, Bozzo M, Pardi G, Fumero R 1998 Blood flow through the ductus venosus in human fetus: calculation using Doppler velocimetry and computational findings. Ultrasound Med Biol 24:477-487

26. Kiserud T, Hellevik LR, Hanson MA 1998 Blood velocity profile in the ductus venosus inlet expressed by the mean/maximum velocity ratio. Ultrasound Med Biol 24:1301-1306

27. Skjaerven R, Gjessing HK, Bakketeig LS 2000 Birthweight by gestational age in Norway. Acta Obstet Gynecol Scand 79:440-449

28. Johnsen SL, Rasmussen S, Wilsgaard T, Sollien R, Kiserud T 2006 Longitudinal reference ranges for estimated fetal weight. Acta Obstet Gynecol Scand 85:286-297

29. Rohrer F 1908 [A new formula for the determination of the body abundance]. Ges Anthropol 39:5-8

30. Gill RW, Trudinger BJ, Garrett WJ, Kossoff G, Warren PS 1981 Fetal umbilical venous flow measured in utero by pulsed Doppler and B-mode ultrasound. I. Normal pregnancies. Am J Obstet Gynecol 139:720-725

31. Boito S, Struijk PC, Ursem NT, Stijnen T, Wladimiroff JW 2002 Umbilical venous volume flow in the normally developing and growth-restricted human fetus. Ultrasound Obstet Gynecol 19:344-349

32. Kiserud T, Kilavuz O, Hellevik LR 2003 Venous pulsation in the fetal left portal branch: the effect of pulse and flow direction. Ultrasound Obstet Gynecol 21:359-364

33. Sutton MG, Plappert T, Doubilet P 1991 Relationship between placental blood flow and combined ventricular output with gestational age in normal human fetus. Cardiovasc Res 25:603-608

34. Kiserud T, Ebbing C, Kessler J, Rasmussen S 2006 Fetal cardiac output, distribution to the placenta and impact of placental compromise. Ultrasound Obstet Gynecol 28:126-136

35. Nicolaides KH, Soothill PW, Clewell WH, Rodeck CH, Mibashan RS, Campbell S 1988 Fetal haemoglobin measurement in the assessment of red cell isoimmunisation. Lancet 1:1073-1075

36. Doughty I, Sibley C 1995 Placental transfer. In Spencer J, Rodeck C (eds) Fetus and Neonate Physiology and Clinical application. Vol 3: Growth. Cambridge University Press, Cambridge, New York, Melbourne, pp 3-29

37. Jacobsson H, Jonas E, Hellstrom PM, Larsson SA 2005 Different concentrations of various radiopharmaceuticals in the two main liver lobes: a preliminary study in clinical patients. J Gastroenterol 40:733-738

38. Pennati G, Bellotti M, De Gasperi C, Rognoni G 2004 Spatial velocity profile changes along the cord in normal human fetuses: can these affect Doppler measurements of venous umbilical blood flow? Ultrasound Obstet Gynecol 23:131-137 